\title{
FORMALISM AND REALISM IN CAMPAIGN FINANCE LAW
}

R. v Mackinlay [2018] UKSC 42; [2018] 3 W.L.R. 556 addressed a narrow question of statutory construction, with implications for two weighty influences upon elections: party support of local candidates, and campaign funding. The case considered an interlocutory pure question of law for an ongoing criminal prosecution. The Supreme Court imposed statutory reporting restrictions and answered the legal question without applying its conclusions to the specific facts of the case. Nevertheless, the facts are important for the general substantive context (at [3]). In issue was whether a candidate must explicitly authorise campaign resources that are provided to the candidate gratis ("notional expenditures") for the resources to qualify as candidate "election expenses" under the Representation of the People Act 1983 (RPA). While Mackinlay rightly concluded that such notional expenditures do not require authorisation to be treated as candidate election expenses, the Supreme Court undertook a tortured reading of statutory language to avoid engagement with substantive political realities. Its unwillingness to face these underlying issues may in time undermine the regulatory regime.

Campaign financing by individual candidates (under the RPA) and political parties (under the Political Parties, Elections and Referendums Act 2000 (PPERA)) is extensively regulated. Under PPERA, s. 72(7), if a party expenditure would also qualify as a candidate expenditure, it is attributed to the candidate rather than the party for regulatory purposes. Parties frequently provide extensive campaign support to candidates in competitive local elections, so this distinction has great significance for compliance with spending and reporting requirements. Attributing functionally local spending to a national party may allow funders to use the party as a conduit for shadow donations and thereby exert disproportionate control over candidates. Such sleight of hand may likewise allow candidate campaigns to circumvent expenditure ceilings. Camouflaging local expenditures as party expenditures may also grant donors greater influence over parties (by enabling donors to provide funding for the critical purpose of local campaigning), or give parties control over candidates (as party funding can be deployed or withheld to incentivise loyalty to the party).

These complexities require courts to balance precise statutory interpretation with the practical ends of campaign finance regulation. Narrowly technical readings may allow sophisticated actors to manipulate the resources' formal statutory classification and thereby conceal their real political impact. Such contrivances thwart the purposes of campaign 
finance regulation: preventing any entity from having excessive and undisclosed electoral influence.

The Supreme Court in Mackinlay eschewed any pragmatic considerations. It asserted that the text of the RPA wholly determines when party expenditures are notional expenditures that candidates must treat as election expenses. Two RPA provisions were of central relevance. Section 90ZA(4) provides that election expenses may be incurred by the candidate, her election agent, or any person authorised by the candidate or her agent to incur expenses. Section 90C provides that if the notional expenditure is (1)(a) either (i) transferred to the candidate or (ii) "made use of by or on behalf of the candidate" in (b) circumstances that, were they "actually incurred by or on behalf of the candidate", would be election expenses, then (2) the notional expenditure "shall be treated....as incurred by the candidate". In effect, under s. 90C notional expenditures are statutorily identical to actual expenditures made by the candidate or her agents. Classifying notional expenditures as election expenses prevents third-party entities (including parties) from circumventing limitations and reporting requirements upon candidates' expenditures by spending for them, rather than making formal donations to the candidate.

Cutting through the statutory thicket, the question was straightforward: should notional expenses qualify as candidate election expenses only if such use was formally authorised by the candidate or an agent? The Supreme Court unequivocally rejected the need for authorisation: there is nothing in s. 90C that indicates the s. 90ZA(4) authorisation requirement must be satisfied to treat notional expenditures as election expenses (at [19]). The Supreme Court reasoned that s. 90C alone establishes necessary and sufficient conditions for notional expenditures to qualify as election expenses. These criteria are: (1) provision of the asset at a discount; (2) use by or on behalf of the candidate; and (3) an expense that, had it been paid for by the candidate, would qualify as an election expense (at [18]).

The Court asserted that it engaged only in statutory construction, and declaimed reliance on consequentialist reasoning (at [27]). Dissonance in the Court's own reasoning shows that this does not ring quite true. The judges carefully noted that notional expenditures cannot qualify as election expenses unless they are "used by or on behalf of candidate[s]". They then observed that use of assets for a campaign cannot satisfy this condition without "some positive activity by the candidate" (or her agent) (at [25]). Yet the claim that to act on behalf of someone during a campaign requires their consent is a substantive claim regarding 
political realities, especially as "behalf" is not a defined term in the RPA. Advocacy or service could be performed on "behalf" of a candidate - promoting their agenda or advancing their interests - without their (formal) consent. One can speak on a person's behalf in their favour without their approval, as well as speak as their agent. In the campaign context, gratis support might be provided to a candidate as resources or integrated facilitation, or through independent advocacy or other distinctly beneficial action that does not require coordination. Such activities might be plausibly characterised as on "behalf" of the candidate.

Mackinlay artificially differentiated between actions on "behalf" of a candidate and actions "for the benefit" of a candidate, indicating the conjunctive requirement of $\mathrm{s}$. 90C(1)(a)(ii) (notional expenditure for "use or benefit" of a candidate) and s. 90C(1)(b) (expenditure "by or on behalf of the candidate" will qualify if it would be an election expense had it actually been incurred by the candidate). The Court noted (at [25]) this means that acting on behalf of a candidate will usually involve substantive conditions that would likely also satisfy the authorisation requirement of s. 90ZA(4). To sustain this analysis, however, the Court committed a logical fallacy: it suggested that an asset is unlikely to be provided on behalf of a candidate if the candidate "positively refuses to accept the benefit" (at [25]). The only alternative to positive rejection the Court entertained is affirmative acceptance. Yet the trickiest scenarios involve ambiguity or silence: can a notional expenditure (say, spent by a party to benefit a candidate) be an election expense when the candidate has done nothing to affirm its use? Strangely, the Court acknowledged such possible relationships between funders and candidates when discussing regulation of donations (at [26], recognising the possibility of donor support of which the candidate is unaware), but declined fully to integrate these reflections into the reading of s. 90C. The Court could have more fully contextualised legal consideration of notional expenditures by considering the statutory treatment of donations, but this would have required considering the purpose of the regulatory regime rather than merely the statutory language.

The strangely artificial nature of the Court's reasoning aside, Mackinlay reached the right legal conclusion. Section 90C establishes a comprehensive test of when notional expenditures qualify as election expenses, and there are other statutory hints that the authorisation requirement ought not apply to it. For example, s. 90ZA(4), unlike s. 90ZA(1)-(3), does not make reference to s. $90 \mathrm{C}$. Likewise, s. $90 \mathrm{C}(2)$ (a) refers to notional expenditures being treated as those incurred by the candidate, whereas s. 90ZA generally refers to expenses incurred, 
implying that s. $90 \mathrm{C}$ is not meant to satisfy s. 90ZA requirements unless explicitly provided (as in s. 90ZA(2) with regard to the need for an expense to be specified in Part 2 of Schedule $4 \mathrm{~A})$.

Yet the more pressing issue is whether requiring authorisation for notional expenditures serves the purpose of the regulatory regime. The regime should facilitate clear identification of relationships between political stakeholders and use expenditure reporting and limits to guarantee fair elections. Such considerations suggest that authorisation should not be required to treat notional expenditures as candidate election expenses. Allowing informal support to be classified under other headings would create a financing grey zone that could undermine statutory oversight of elections, especially where the status of the expenditure might be manipulated through discretionary authorisation. Ironically, the Court's interpretation of specific terms in Mackinlay - particularly the word "behalf" - might inadvertently curb the regulatory regime, by implying that only a narrow range of notional expenditures (those affirmatively accepted by a candidate) could qualify as candidate election expenses.

The judicial impulse to avoid substantive assessment of electoral politics and confine itself to minimalist statutory interpretation may have legitimate political foundations. It is representatives and their constituents alone who have ultimate policy-making authority in the UK; election law does not merely set first-order policy, but establishes the higher-order terms by which policy is created. Thus election law is, arguably, a domain in which scrupulous judicial deference to parliamentary will is especially important. Yet the centrality of fair electoral procedure to legitimate future selection of representatives means that it is likewise important that the Court prioritizes integrity and coherence in interpreting the election law statutory regime. Mackinlay showed a disinclination to substantively acknowledge these issues, a disinclination that could undermine democracy in the future. 